\title{
Utilization Iron Filings and Microwave Heating in Roughening the Surface of Smoothed Coarse Aggregates
}

\author{
Laith Mohammed Ridha Mahmmod ${ }^{1}$, Wajde, S. S. Alyhya ${ }^{1^{*}}$, Zainab, M. R. Abdul Rasoul ${ }^{1}$ and \\ Abdulrasool T. Abdulrasool ${ }^{2}$ \\ ${ }^{1}$ University of Kerbala, College of Engineering, Civil Engineering Dept. Karbala 56001, Iraq \\ ${ }^{2}$ MSc student, University of Kerbala, College of Engineering, Civil Engineering Dept. Karbala 56001, Iraq \\ * Corresponding author E-mail : Wajde.alyhya@uokerbala.edu.iq
}

\begin{abstract}
Properties of coarse aggregate such as texture have a significant influence on the performance of fresh and hardened concrete. A smooth surface can enhance workability, yet a rougher one offers a stronger bond between aggregate and paste, resulting in higher strength. This research aims to roughen the texture of white smoothed aggregate by using cement-iron filings mortar with the aid of microwave maturation to accelerate the adhesion process of mortar-aggregate surface. The mortar was prepared by mixing an equal weight of cement and iron filings, of a particular size, with sand. Four different periods (2, 4, 6 and 8 mints.) of microwave treatment in addition to water curing were considered plus one reference mortar which cured in only air for $24 \mathrm{hrs}$. The treated aggregate was then used for casting concrete specimens with a w/c ratio of 0.5 in which their properties being determined by means of density, compressive and tensile strengths observations. The main findings revealed that the concrete specimens contained microwave treated aggregate attained higher compressive strength compared with those treated in the air. Data also showed that concrete specimens with microwave treated aggregate possess better tensile properties as a consequence of the improvement in the transition zone.
\end{abstract}

Keywords: Coarse aggregate; Compressive strength; Iron filings; Microwave; Tensile strength; Texture.

\section{Introduction}

Aggregate could typically occupy nearly three-quarters of concrete volume and has a substantial effect on its fresh and hardened properties. Surface aggregate texture, which is the relative smoothness or roughness of aggregate particle shows a significant role in increasing the bond between cementing materials and aggregate particles. A smooth surface texture offers high workability owing to lower existing friction, while a rough surface one provides a gripping with the cementing material producing a stronger bond, and thus creating a stronger mix [1][2]. In the last few decades, the removal of industrial and agricultural wastes has concerned human beings due to the arising environmental impact of these wastes [3], which was the main driver for the worldwide agitation towards sustainable construction. This, as well as the gradual decline and high cost of the naturally available aggregate, forced the construction industry to enhance the properties of the existing materials or seek for alternatives [4]. These can decrease the space required for the landfill disposal and alleviate the consumption of raw natural resources. Iron filings, which is mostly a by-product waste of the finished iron products, is a gifted material to be employed in concrete. The fine iron filings should be properly collected and stored as it can be effortlessly flying causing an environmental pollution and health problem. Recycling of iron filings will avoid the ending up of these wastes in landfills and offer eco-friendly, affordable, solid stone for countless uses [5].

A great deal of studies aimed at the recycle of iron waste in the new construction materials development [9-13]. Several studies revealed that the use of iron waste as a recycled aggregate in concrete can be technically feasible and can improve its mechanical properties $[9,12,13]$. Iron waste comprises mainly very fine materials such as iron oxides, silica, alumina, and other minor minerals. This composition determines the potentials as a construction material, such as a fine aggregate in producing cementitious materials $[9,12,13]$. In this context, the previous work suggests the use of iron waste as a natural aggregate or cement replacement in mortars production. Ismail and Al-Hashmi [6] evaluated the opportunity of using simultaneously the mixed granulated plastic and iron filings waste materials as a partial replacement for fine aggregate in concrete. In their study, the concrete composites were prepared by mixing type I Portland cement with the aggregates. Three fractions weight of iron filings $(30,40$, and $50 \%)$ and $5 \%$ of granulated plastic waste were used. The main findings stated that the plastic waste materials and iron filings mixture could be effectively utilized as a partial fine aggregate substitution in concrete composites. In another study, Ismail and Al-Hashmi [7] also concluded that the use of iron filings waste to partially replace fine aggregate in various concrete mixes can offer higher compressive strength values than those of the plain mixes values. Olutoge et al., [8] conducted a research to examine the use of iron filings as a partial fine aggregate replacement on the mechanical properties of concrete. Various concrete specimens (cubes, cylinders, and prisms) were tested for compressive, splitting tensile and flexural strengths at different levels of fine aggregate replacement (0\% (reference mix), 10\%, 20\% and 30\%) (by weight) with iron filings prior to conventional water curing for 28 -days. The findings displayed that there was an increase in the concrete compressive strength by $3.5 \%$ and $13.5 \%$, for the 10 and $20 \%$ fine aggregate substitutions respectively. In addition, the splitting tensile strength found to be increased by $12.7 \%$ and $5 \%$, for the 10 and $20 \%$ 
fine aggregate substitutions respectively when compared to the control mix. The same trend is applicable to the concrete flexural strength as it increased by $11.1 \%$ and $4.8 \%$ for the 10 and $20 \%$ substitution levels respectively in comparison to the control mix. Goyal1 et al., [9] studied in an experimental investigation the influence of fine aggregate partial replacing by iron tailing of levels $10 \%, 20 \%, 40 \%, 60 \%$ and $80 \%$ on the mechanical properties of M25 grade concrete. Results found that as the iron ratio increased, the workability of the mix decreased, resulting in a lower compressive strength of the concrete. Ghannam et al., [5] investigated the partial replacement of fine aggregate by iron powder (IP) and granite powder (GP) in various proportions (i.e. $5 \%, 10 \%, 15 \%$, and $20 \%$ ). It was detected that the substitution of $10 \%$ of fine aggregate weight with IP and GP in concrete represents the optimum percentage that produced concrete with the best compressive and flexural strengths. The same results were also stated by Zhu et al.,[10]. Tian et al., [11] evaluated the modified performance of concrete with iron ore tailings in order to solve the shortage in the natural sand by exploiting such industrial waste. Sarsaam [4] examined the effect of the partial weight cement replacement by three kinds of nanomaterials (iron filings dust, coal fly ash and limestone) on the concrete pavement properties. The obtained results showed that the substitution of coal fly ash and limestone dust can cause a reduction in the flexural strength. In contrast, iron filings addition produced concrete with higher flexural strength. Alzaed [12] reported similar results from his study.

Apart from the traditional water curing conducted in all the above research, microwave heating is a highly efficient technique in curing cementitious materials [13]. These materials have outstanding dielectric properties, which enable them to absorb efficiently the microwave energy and convert instantaneously into heat [14]. A significant number of studies has revealed that curing by microwave, which is considered as an innovative material processing stands as a strong candidate in developing rapid early strength for cement-based materials [17][18][19][20]. Basically, the dielectric permittivity of cement-based materials facilitates the interaction with microwave radiation, which leads to fast heating [21]. Unlike conventional heating, microwave heating is of high efficiency in heating various materials particularly those with dielectric nature [18] [20]. Prommas and Rungsakthaweekul [15] explained an appropriate MWs curing process for rapid thermal concrete curing application that could be implemented for the purpose of strength enhancement.

It is unfortunate to note that none of the above studies nor any research work (to the best knowledge of the author) has explored the effect of using cement-iron filings mortar to enhance the coarse aggregate surface treating by microwave. Since iron filings are common kinds of non-biodegradable solid wastes resulting from superfluous materials from numerous industrial processes, the knowledge of the combined influence (surface coating and microwave curing) on the concrete properties is worth to be considered. Thus, the purpose of this current study was to experimentally investigate the effect of using iron filings-cement mortar in roughening the smoothed coarse aggregate surface matured by microwave on some concrete mechanical properties.

\section{Experimental work}

\subsection{Materials}

In this study, type V Portland cement was utilized with the compositions given in Table 1 (it performs according to ASTM C150) [16]. Locally available fine aggregate with a particle size less than $4.75 \mathrm{~mm}$ was used. The iron filings waste was obtained from the iron factory as it is usually produced thousands of tons from the ironsmith processes. The chemical composition of the iron filings is given in Table 2 .
Table 1: Chemical compositions Portland cement V*

\begin{tabular}{|c|c|c|c|c|c|c|c|}
\hline \multicolumn{7}{|c|}{ Components' Proportion, \% } \\
\hline $\begin{array}{c}\mathrm{SiO} \\
2\end{array}$ & $\begin{array}{c}\mathrm{Fe} 2 \mathrm{O} \\
3\end{array}$ & $\begin{array}{c}\mathrm{A} 12 \mathrm{O} \\
3\end{array}$ & $\begin{array}{c}\mathrm{Ca} \\
\mathrm{O}\end{array}$ & $\begin{array}{c}\mathrm{Mg} \\
\mathrm{O}\end{array}$ & $\begin{array}{c}\mathrm{SO} \\
3\end{array}$ & $\begin{array}{c}\text { Loss } \\
\text { on } \\
\text { ignitio } \\
\mathrm{n}\end{array}$ & $\begin{array}{c}\text { Insolubl } \\
\mathrm{e} \\
\text { residue }\end{array}$ \\
\hline 21.5 & 5.3 & 4.2 & 61.0 & 1.5 & 1.9 & 2.3 & 0.9 \\
\hline
\end{tabular}

* Source: National Center for Construction Laboratories, Iraq

Table 2: Chemical compositions of iron filings *

\begin{tabular}{|c|c|c|c|c|c|c|}
\hline \multicolumn{7}{|c|}{ Components' Proportion, \% } \\
\hline $\mathrm{C}$ & $\mathrm{Si}$ & $\mathrm{Mg}$ & $\mathrm{S}$ & $\mathrm{P}$ & $\mathrm{Mn}$ & $\mathrm{Fe}$ \\
\hline 3.17 & 2.82 & 0.07 & 0.03 & 0.04 & 0.35 & 93.52 \\
\hline
\end{tabular}

* Source: National Center for Construction Laboratories, Iraq

\subsection{Experimental set-up}

Mortar, which is used for coating coarse aggregate, were prepared using an equal weight of Portland cement type $\mathrm{V}$ and iron filings passing sieve No. 150 to be mixed with sand and tap water. The ratio of cement plus iron filings to sand was fixed at 1:3 following the ASTM C305 standard [17], while the w/c was fixed at 0.50 . After mortar's ingredients were mixed, it becomes ready to coat the coarse aggregate. Two various procedures were used to cure the treated aggregate. In the first procedure, the coated aggregates were left for curing in the laboratory environment for $23 \pm 1 \mathrm{~h}$. While in the second procedure, the coated aggregates were cured in the microwave for four various times of 2, 4, 6 and 8 mins. The coated aggregates from the two procedures were used to prepare the concrete mixes to achieve the intended scope of this study. All concrete mixes designations, as well as details, are given in Table 3. Specimens of concrete mixes were cast, de-moulded and cured in water until the age of testing. The investigated parameters of this study were density, compressive strength, and tensile strength. All specimens were soaked in water of controlled temperature equal to $24.0 \pm 2.0 \circ \mathrm{C}$ until testing time.

Table 3: Details of the prepared mortar for coating

\begin{tabular}{|c|c|c|c|c|c|}
\hline $\begin{array}{l}\text { Mix } \\
\text { designati } \\
\text { on } \\
\end{array}$ & $\mathrm{CA}(1)$ & CM2(2) & CM4(3) & CM6(4) & CM8(5) \\
\hline $\begin{array}{l}\text { Surface } \\
\text { condition } \\
\text { of } \\
\text { aggregat } \\
\text { e used }\end{array}$ & $\begin{array}{l}\text { Coate } \\
d \\
\text { surfac } \\
\text { e }\end{array}$ & $\begin{array}{l}\text { Coated } \\
\text { surface }\end{array}$ & $\begin{array}{l}\text { Coated } \\
\text { surface }\end{array}$ & $\begin{array}{l}\text { Coated } \\
\text { surface }\end{array}$ & $\begin{array}{l}\text { Coated } \\
\text { surface }\end{array}$ \\
\hline $\begin{array}{l}\text { Curing } \\
\text { regime of } \\
\text { coating } \\
\text { mortar }\end{array}$ & $\begin{array}{l}24 \mathrm{hr} \\
\text { in Air }\end{array}$ & $\begin{array}{l}\text { Microwa } \\
\text { ve } \\
\text { ( } 2 \text { mins.) }\end{array}$ & $\begin{array}{l}\text { Microwa } \\
\text { ve } \\
\text { (4mins.) }\end{array}$ & $\begin{array}{l}\text { Microwa } \\
\text { ve } \\
\text { (6mins.) }\end{array}$ & $\begin{array}{l}\text { Microwa } \\
\text { ve } \\
(8 \mathrm{mins} .)\end{array}$ \\
\hline
\end{tabular}

1: Concrete mix with coated surface coarse aggregate with cementiron filings mortar cured at air temperature for $24 \mathrm{hr}$.

2: Concrete mix with coated surface coarse aggregate with cementiron filings mortar cured by microwave for 2 mins.

3: Concrete mix with coated surface coarse aggregate with cementiron filings mortar cured by microwave for 4 mins.

4: Concrete mix with coated surface coarse aggregate with cementiron filings mortar cured by microwave for 6 mins.

5: Concrete mix with coated surface coarse aggregate with cementiron filings mortar cured by microwave for 8 mins.

\section{Test results and discussions}

\subsection{Density}

The density test results revealed that the coated coarse aggregates concrete specimens cured by microwave have a moderately higher density as the time of curing by microwave increase up to $8 \mathrm{mins}$ (see Figure 1). For the coated coarse aggregate concrete mixes (i.e. $\mathrm{CM} 2, \mathrm{CM} 4)$, the density values were higher than that of the coated smoothed surface aggregate mix (CA) cured by air. This could be 
owing to the effect of high-density of iron filings, which causes to produce heavier concrete. On the other hand, the densities of the coated coarse aggregate concrete mixes (i.e. CM6, CM8) were lower than the concrete mixes with coated smoothed surface aggregate mix (CA) cured by air.

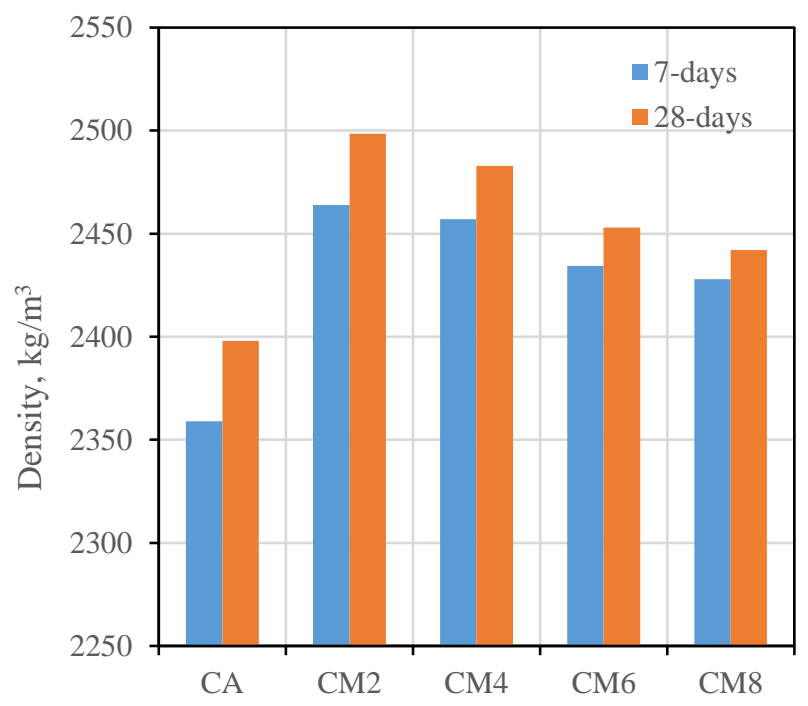

Mix designation

Fig. 1: The 7 and 28 days densities of various concrete mixes

\subsection{Compressive strength}

The 7 and 28 days compressive strengths of concrete cubes were determined as the average of three measurements. They are given in Table 4 and revealed in Figure 2. As expected, the compressive strength develops with age progress due to the hydration process of cementing materials.

Table 4: Compressive strength of the prepared concrete mixes

\begin{tabular}{|c|c|c|}
\hline \multirow{2}{*}{ Mix designation } & \multicolumn{2}{|c|}{ Compressive strength, MPa } \\
\cline { 2 - 3 } & 7 days & 28 days \\
\hline CA & 11.3 & 18.8 \\
\hline CM2 & 20.7 & 27.4 \\
\hline CM4 & 21.3 & 28.2 \\
\hline CM6 & 25.8 & 29.1 \\
\hline CM8 & 27.9 & 32.8 \\
\hline
\end{tabular}

For the sake of compressive strength comparisons, two behaviours can be noticed associated with the effect of surface coating and microwave curing. Generally, for coated smoothed surface aggregate mix (CA) cured by air, as shown in Figure 2, there were substantial differences in the compressive strength at all ages ( 7 and 28 days) when compared to other mixes that have coated coarse aggregate and cured for various times in microwave. Later (at age 28 days), these differences started to decrease, and the strengths approached each other. In other words, it can be concluded that the coated coarse aggregate concrete specimens with iron fillingcement mortar and cured by microwave for various times provided better performance in comparison with those specimens cured in air. In more details, the results demonstrate that as the curing time by microwave increases, the tendency of 7 days strength values exceeds the values of the concrete mix that were cured in air by 9.0 , 10,15 and $17 \mathrm{MPa}$, respectively. This tendency could be due to the rough effect of the coarse aggregate surfaces that arise from using cement-iron

filings mortars that enhances the bond between aggregate particles and cementing materials. Neville [1] explained that the increase in the compressive strength is attributed to the high strength and density of iron. Dionys et al. [18] stated that throughout the hydration process, the added iron filling materials lead to a rough film formation, which enhancing the co-matrix as the iron filings intermingle with cement hydrate, causing an increase in the compressive strength. In addition, it can be concluded that the concrete compressive strength increases gradually as the curing time by microwave increases up to $8 \mathrm{~min}$.

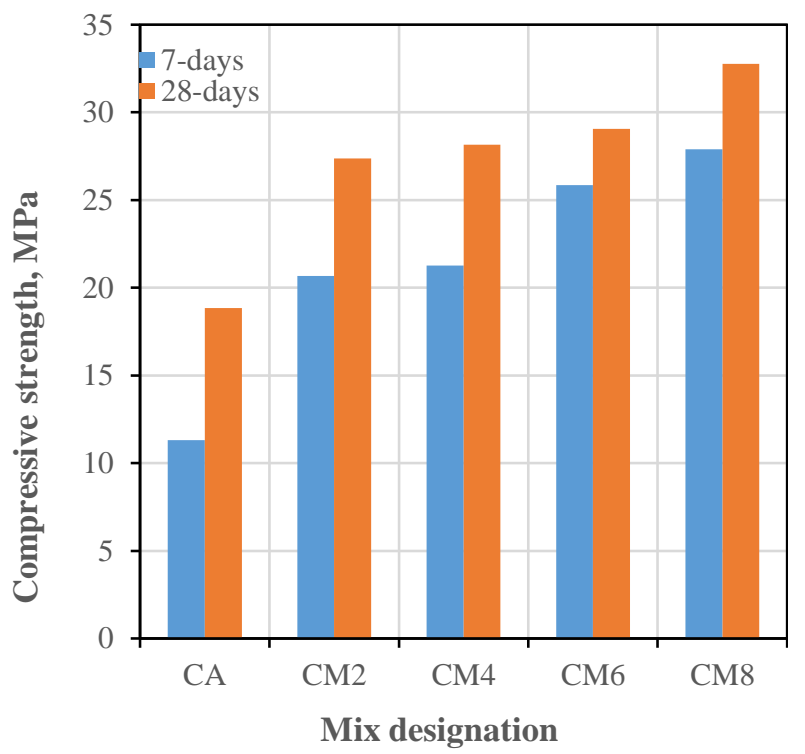

Fig. 2: The 7 and 28 days compressive strength of various concrete mixes

\subsection{Splitting tensile strength}

The splitting tensile strength results for all mixes are shown in Figure 3. All mixes presented continuous improvement in strength with different rates in the final values. The control mix (NA), which made with natural smoothed surface coarse aggregate, has nearly the lower splitting tensile strength magnitude when compared to other concrete mixes made with coated aggregate at the same ages except for the one that has coated coarse aggregate cured for 4 minutes in the microwave. It is thought that the surface coatings of the treated smoothed coarse aggregate were the reason behind the recorded decline in tensile strength. Moreover, the visual observing of the specimens after testing showed the separation of the coated mortar from coarse aggregate surfaces, especially for those concrete mixes cured in

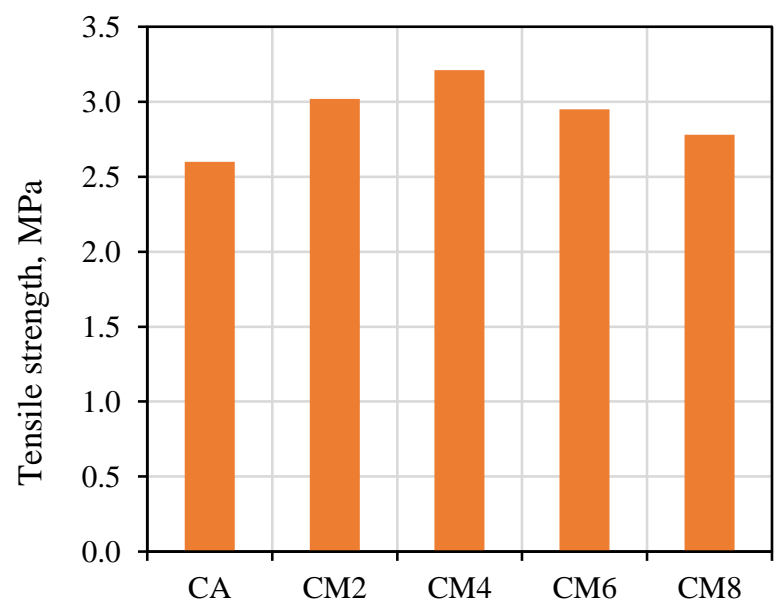

Mix designation

Fig. 3: The 28 days splitting tensile strength of various concrete mixes

the air could be the reason behind their lower mechanical properties (i.e. lower compressive and splitting tensile strength).

The bond among cement, iron filings and aggregate is a consequence of chemical reaction between cement paste and 
aggregate as well as mechanical interlocking of hydration products with the aggregate surface. Although aggregate is considered as an inert material, many investigators had been reported that chemical reactions could occur. Both bond causes i.e. chemical reaction and mechanical interlocking, were proposed to be neutralized by coarse aggregate coatings. According to the obtained findings, coating the smoothed coarse aggregate with cement-iron filling mortar was effective in improving the transition zone strength between mortar and aggregate. Comparable trends for the effect of roughening coarse aggregate on concrete strength had been reported by many researchers.

\section{Conclusions}

The following conclusions could be drawn according to the obtained findings:

Using cement-iron filings mortar to coat the smoothed coarse aggregate results in a higher density of concrete.

The interface zone characteristics are highly affected by the bond between cement-iron filings mortar and aggregate. However, the influence of the transition zone properties on the concrete mechanical properties is still vague. This is mainly attributed to the difficulty in determining the actual transition zone properties.

The effects of cement-iron filings mortar as coatings for the smoothed coarse aggregate on the mechanical properties of concrete have been considered. The cement-iron filings mortar layer was effective in enhancing the bond between cement mortar and coarse aggregate throughout the improvement in the compressive and splitting tensile strengths.

Microwave curing allows cement-iron filings mortar as aggregate coatings for the preparation of various concrete mixes. This seems to be a promising way to enhance the performance of smoothed coarse aggregate in concrete mixes.

\section{References}

[1] Neville AM, Brooks JJ. Concrete Technology. 2nd ed. UK: Pearson Education Ltd.; 2010.

[2] Yeggoni M, Button JW, Zollinger DG. Influence of coarse aggregate shape and surface texture on rutting of hot mix asphalt 1994:148.

[3] Welsh Assembly Government. Towards zero waste 2010:92.

[4] Sarsam SI. Influence of nano-materials addition as partial replacement of cement in the properties of concrete pavement 2016;2:1-5.

[5] Ghannam S, Najm H, Vasconez R. Experimental study of concrete made with granite and iron powders as partial replacement of sand Sustain Mater Technol 2016;9:1-9.

[6] Ismail ZZ, Al-Hashmi EA. Validation of using mixed iron and plastic wastes in concrete. 2nd Int Conf Sustain Constr Mater Technol 2010:393-403.

[7] Ismail ZZ, Al-hashmi EA. Reuse of waste iron as a partial replacement of sand in concrete. Waste Manag 2008;28:2048-53.

[8] Olutoge F, Onugba M, Ocholi A. Strength properties of concrete produced with iron filings as a sand replacement. Br J Appl Sci Technol 2016:18:1-6.

[9] Goyal S, Singh K, Hussain A, Singh PR. Study on partial replacement of sand with iron ore tailing on compressive strength of concrete. Int J Res Eng Adv Technol 2015;3:243-8.

[10] Zhu Z, Li B, Zhou M. The influences of iron ore tailings as a fine aggregate on the strength of ultra-high performance concrete. Adv Mater Sci Eng 2015;2015:1-7.

[11] Tian Z, Zhao Z, Dai C, Liu S. Experimental study on the properties of concrete mixed with iron ore tailings. Adv Mater Sci Eng 2016.

[12] Alzaed AN. Effect of iron filings in concrete compression and tensile strength. Int J Recent Dev Eng Technol 2014;3:121-5.

[13] Elakkiya K, Uma N, Govandan A. Effect of thermal and microwave oven curing on concrete. Indian Journal Sci Res 2018;17:262-7.

[14] Makul N, Rattanadecho P, Agrawal DK. Applications of microwave energy in cement and concrete - A review. Renew Sustain Energy Rev 2014;37:715-33.

[15] Prommas R, Rungsakthaweekul T. Effect of microwave curing conditions on high strength concrete properties. Energy Procedia 2014;56:26-34.
[16] ASTMComitteeC150. Standard test methods for chemical analysis of hydraulic cement. Annu B ASTM Stand 2007:1-8.

[17] ASTMCommitteeC305. Mechanical mixing of hydraulic cement pastes and mortars of plastic consistency. Annu B ASTM Stand 2007:495-7.

[18] Van Gemert D, Czarnecki L, Maultzsch M, Schorn H, Beeldens A, Łukowski $\mathrm{P}$, et al. Cement concrete and concrete-polymer composites: Two merging worlds: A report from 11th ICPIC Congress in Berlin, 2004. Cem Concr Compos 2005;27:926-33. 